\title{
Modern aspects of the development of financial inclusion in rural areas of the Russian Federation
}

\author{
Svetlana Podgorskaya* \\ Federal Rostov Agrarian Scientific Center (FRASC), 346735, Institutskaya str., 1, Rassvet village, \\ Rostov region, Russia
}

\begin{abstract}
The article considers financial inclusion as the most important means of achieving sustainable comprehensive economic growth. It is established that in the new model of sustainable development of rural areas, the financial involvement of households and small and medium-sized businesses is of particular importance. However, in Russia, among all segments of the population, the most excluded category from financial and economic interaction is precisely rural residents. The main reasons for this situation are digital inequality in the form of low availability of digital communications (Internet and mobile communications) for the rural population, the low level of digital and financial competencies of the villagers, and the low level of income of rural households. Despite the government's policy to increase the financial accessibility of banking services and eliminate digital inequality, in regulatory and policy documents, references to rural areas are either indirect or absent. Today, there is a boom in the digitalization of financial services; the level of development of information technologies allows you to create more convenient, efficient and mobile products that do not require visits to bank branches and face-to-face consultations. At the same time, such digitalization can become a threat to the development of financial inclusion in rural areas. In this regard, are needed special programs to improve the financial and digital literacy of the rural population, as well as a system of accessible consulting support on lending issues.
\end{abstract}

\section{Introduction}

The world scientific community defines the concept of inclusive economic growth as a means of achieving sustainable development of modern civilization [1, 2]. It is empirically proven that income inequality in the present time negatively affects the opportunities for sustainable development and inclusive growth in the future, and the prospects for economic growth of a country are directly linked to an increase in the incomes of the poor and middle class. Thus, studies have shown that an increase in the income of the rich by $1 \%$ leads to a decrease in the GDP growth rate in the country by $0.08 \%$ in the next 5 years. While an increase in the incomes of the middle class and the poor can lead to an increase in the GDP growth rate by $0.38 \%[3,4,5]$.

\footnotetext{
* Corresponding author: svetlana.podgorskaya@gmail.com
} 
In the World Economic Forum's Inclusive Development Index (IDI) ranking, presented in January 2017 [6], Russia ranked 13th among 78 developing countries, and in the 2018 ranking it fell to 19th place, although in terms of gross domestic product per capita, it ranked higher in the same group in 9th place [7].

The goals of sustainable inclusive development are increasingly being integrated into the state policy of the Russian Federation, in 2020. The President signed a Decree "On the National development Goals of the Russian Federation for the period up to 2030", in which the national targets are defined: the preservation of the population, the health and well-being of people; opportunities for self-realization and the development of talents; a comfortable and safe environment for life; decent, effective work and successful entrepreneurship; digital transformation.

Against the background of the economic downturn due to the coronavirus pandemic, global economic challenges and geopolitical conjuncture, the Government of the Russian Federation has developed a new strategy for the socio-economic development of Russia until 2030. By May 2021, the Government plans to submit a comprehensive document defining adequate measures of the state economic policy to achieve the national development goals of the Russian Federation.

In addition, in order to promote sustainable development, the Government is developing the "Federal Scientific and Technical Program in the field of environmental development of the Russian Federation and climate Change for 2021-2030", which provides for solving environmental problems and nature conservation based on high-tech technological innovations.

\section{Research methodology}

The empirical base of the research was made up of official data of the state statistics of the Russian Federation, reports of the Ministry of Agriculture, the results of monitoring and surveys of rural residents on the assessment of financial involvement and financial literacy, expert assessments in the works of domestic and foreign scientists. The methodological basis of the research is a systematic approach, according to which financial inclusion is considered as a determinant of the sustainable development of a complex socio-economic system of rural areas. In the course of the research, general scientific methods were used: analysis and synthesis; induction, deduction and analogy; abstraction; generalization; statistical and economic analysis.

\section{Results}

Rural territories make up a significant part of the territory of the Russian Federation, perform the most important national functions that ensure a balanced socio-economic development of the country, increase the competitiveness of its economy, and are the most important resource for sustainable inclusive development.

At the same time, it is in rural areas that the most acute problems are poverty, unemployment, the availability of jobs with decent working conditions, the income of the population, and the availability of social services. Studies show that despite the generally successful practice of implementing the state policy of rural development, the problems of the labor sphere and economic development, the state of rural social infrastructure continues to be unsatisfactory, and often in crisis, and does not change dramatically [8, 9].

The unemployment rate in rural areas has been consistently high for many years and is almost twice as high as in urban areas ( $8 \%$ vs. $4.3 \%$ ). The rural population continues to decline (by 1.7\% in 2021 compared to 2018). The development of social infrastructure has 
remained at the same level for several years. The monthly salary of agricultural workers is only $65.6 \%$ of the average value for the economy of the Russian Federation.

The available resources for a member of a rural family, including all cash and in-kind income to the household, borrowed funds and own savings spent in this period, make up 67\% of the urban level. As a result, almost every third (27\%) villager lives below the poverty line, while among urban residents, the share of the population with monetary incomes below the poverty line is $8 \%$ [10].

The new model of rural development based on the principles of inclusive growth will ensure equal access of the rural population to social benefits and services and economic resources.

The basis for the formation of such a model should be a state policy aimed at ensuring equal opportunities for rural development, access of all segments of the rural population to quality education and health care, economic and financial resources, as well as the formation of inclusive institutions that stimulate the participation of the broad masses of villagers in economic activities and ensure the development of multi-faceted entrepreneurship in rural areas.

The determinant of achieving the Sustainable Development Goals for the period up to 2030 is the financial involvement of the population or financial inclusion. According to UN estimates, it contributes to the achievement of almost half of the Sustainable Development Goals [11], overall economic growth and its sustainability.

The vector of inclusive development in the field of financial security is aimed at involving individuals and small and medium-sized businesses in the financial system (financial transactions).

The institutional framework for the development of financial inclusion in Russia consists of such program documents as: "Strategy for improving financial accessibility in Russia for the period 2018-2020", "Main directions for the development of the financial market of the Russian Federation for the period 2019-2021", "Main directions for the development of financial technologies for the period 2018-2020", "Strategy for improving financial literacy in the Russian Federation for the period 2017-2023".

It should be noted that the goals of rural development are found only in the Strategy of Increasing financial accessibility, in other programs, measures for the development of the financial sector are indirectly related to the village.

Financial inclusion should be considered from the perspective of the availability of financial services and financial resources. In most publications, these categories are not distinguished, in our opinion, this should be done due to their different nature.

Financial inclusion is determined by the availability of financial services and in the modern world is directly related to digitalization. In this regard, the main factors influencing the development of financial engagement are the level of digitalization of the financial sector and communication infrastructure, the level of financial and digital literacy of the population, the development of digital financial technological innovations (FinTech).

According to the McKinsey Global Institute, digital finance alone can benefit billions of people by driving inclusive growth that will add \$ 3.7 trillion to the GDP of emerging economies by 2030.

The development of this form of interaction in rural areas is determined by access to high quality and sustainable Internet and mobile communications. In Russia, since 2014, the Federal Target Program "Elimination of Digital Inequality" has been in operation, which has now been transformed into the National Project "Digital Economy of the Russian Federation". Despite the successful implementation of these projects, there is still a low availability of digital communications for the rural population (Fig. 1), it is expressed not only in the quality and availability of technological infrastructure, but also in the level of digital competencies of users and digital literacy of the rural population. In 2018, the level of 
digital competencies of the rural population of the Russian Federation was estimated at 55\% against $59 \%$ in the urban population [12].

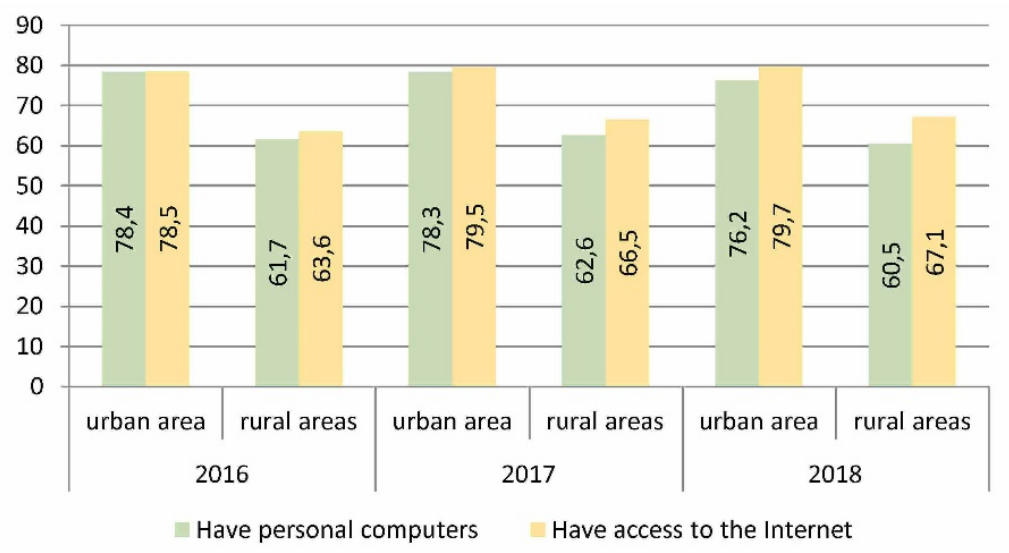

Fig. 1. Dynamics of digitalization of households in the Russian Federation

Note: Compiled by the author on the basis of data from the Federal State Statistics Service

According to the results of the survey of rural residents, $47 \%$ indicated that they do not need to use the Internet, which indicates their low social and economic activity, and 23\% noted an insufficient level of skills (Fig. 2).

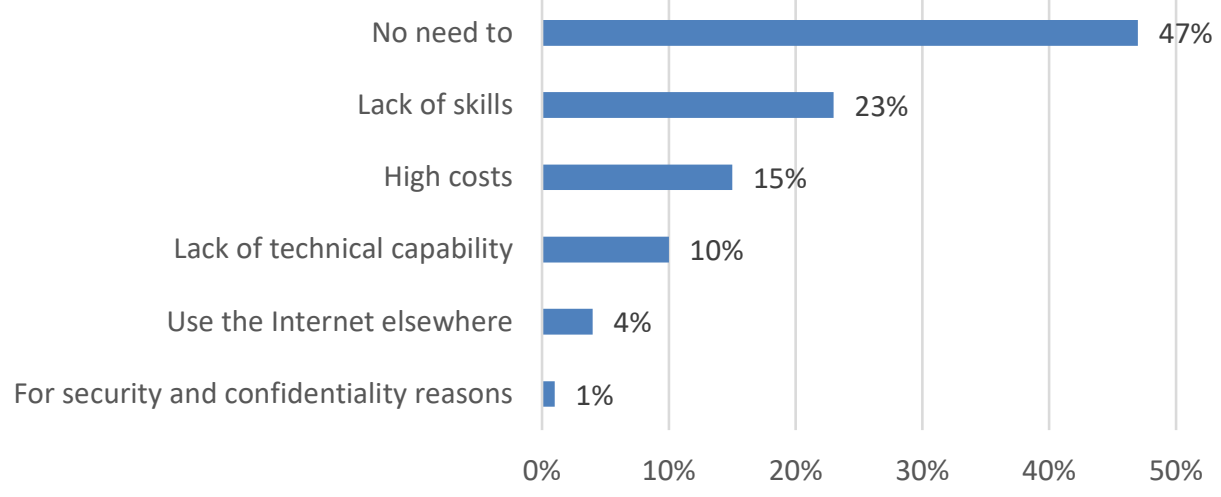

Fig. 2. Results of the survey on the reasons for non-use of the Internet by rural households (2018)

The active transformation of financial services into an online format, paradoxically, can become a factor hindering the development of financial inclusion in rural areas due to the lower level of financial and digital literacy of the rural population. Despite the rapid development of digital financial technologies, it is necessary to create conditions for the development of a branch network of various banks in district centers and to promote the provision of banking services through rural post offices for consulting support of rural residents.

It should be noted that in Russia there is practically no statistics on the involvement of rural residents in financial transactions. For example, among the indicators of the annual monitoring of financial accessibility conducted by the Bank of Russia, there is not a single indicator related to rural areas. In the analytical note for the results of 2019, there is only one reference to the increase in the coverage of rural settlements with physical banking services 
at the expense of post offices to 26.4 thousand units, or by 35\%. In this regard, the average values for the country or regions do not reflect the state of affairs in rural areas at all.

The World Bank monitors the development of financial inclusion in more than 183 countries around the world. Among the numerous indicators, 50 relate to the assessment of the financial involvement of the rural population. To characterize the dynamics of financial inclusion of the rural population of Russia, we use the available Global Findex statistics for 2011-2017. (Fig. 3, Tab. 1) [13].

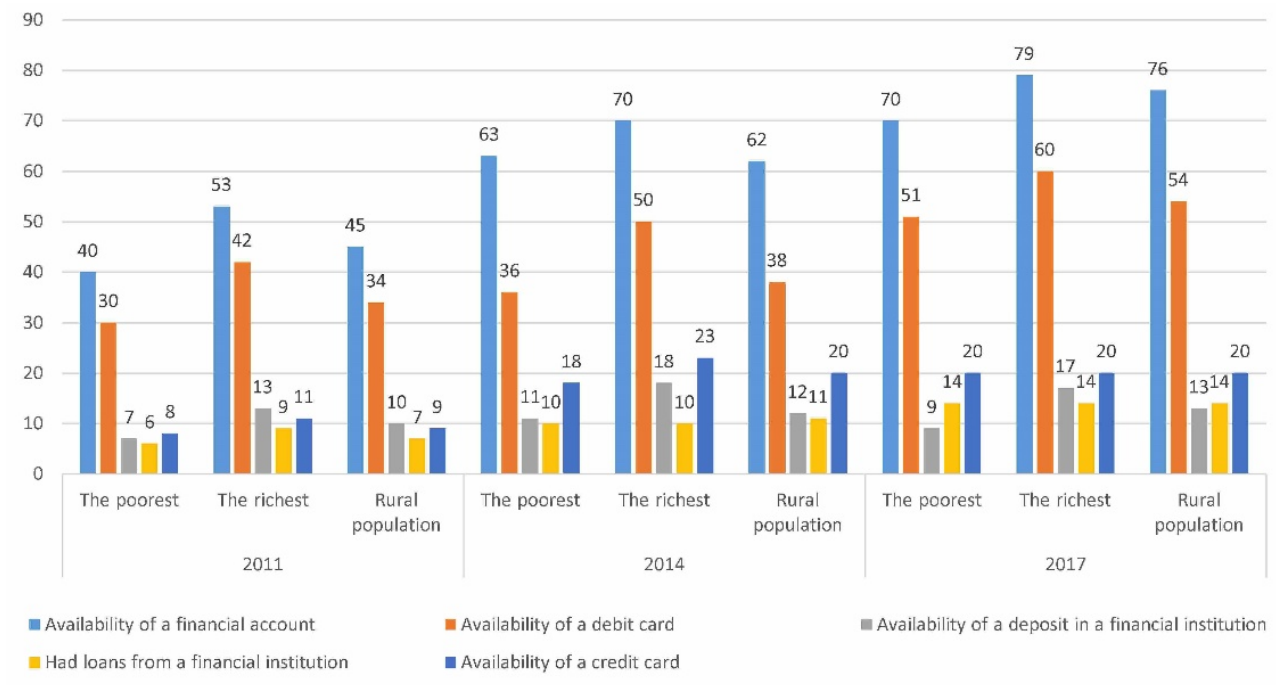

Fig. 3. Development of financial inclusion in rural areas of the Russian Federation in 2011-2017*

Table 1. Use of digital financial services by population groups with different incomes and rural residents, \% *

\begin{tabular}{|l|c|c|c|c|c|c|}
\hline \multicolumn{1}{|c|}{ Indicator } & \multicolumn{3}{|c|}{$\mathbf{2 0 1 4}$} & \multicolumn{3}{c|}{$\mathbf{2 0 1 7}$} \\
\cline { 2 - 7 } & $\begin{array}{c}\text { The } \\
\text { poorest }\end{array}$ & $\begin{array}{c}\text { The } \\
\text { richest }\end{array}$ & $\begin{array}{c}\text { Rural } \\
\text { population }\end{array}$ & $\begin{array}{c}\text { The } \\
\text { poorest }\end{array}$ & $\begin{array}{c}\text { The } \\
\text { richest }\end{array}$ & $\begin{array}{c}\text { Rural } \\
\text { population }\end{array}$ \\
\hline $\begin{array}{l}\text { Used the Internet to pay } \\
\text { bills or make purchases } \\
\text { online }\end{array}$ & 13 & 20 & 13 & 34 & 43 & 32 \\
\hline We paid for utilities online & 72 & 72 & 72 & 77 & 75 & 79 \\
\hline Made digital payments & 46 & 59 & 47 & 64 & 75 & 69 \\
\hline
\end{tabular}

Note: * Compiled by the author based on Global Findex data

The presented data indicate a significant increase in the financial inclusion of the rural population of the Russian Federation, both in the use of basic credit and financial transactions and digital services.

The positive dynamics is confirmed by the monitoring data carried out within the framework of the project of the Ministry of Finance of Russia and the World Bank. In Russia in 2020, 56\% of citizens used digital banking tools to manage their finances; in rural areas, the prevalence of these services is less, and $49 \%$ of villagers use them. Mobile banking applications are the most popular among 51\% of Russians, and the share of Internet banking users was $37 \%$ of the respondents. The study showed that compared to 2018 , there is an explosive twofold growth in remote service customers. 
At the same time, the use of bank cards by rural residents remained at the level of 2017 $74 \%$, the share of depositors among the rural population increased slightly - $16 \%$ compared to $13 \%$ in 2017.

In 2018 and 2019, Russia maintained a high position in the world ranking of financial literacy of the population. Among 17 European countries, it took the 9th place. In the range from 1 to 21, the national average in 2019 was 12.37, for large cities it was 12.64, for rural areas-11.99. At the same time, the self-assessment of financial literacy among the villagers is quite low, $72 \%$ of respondents in the framework of the project of the Ministry of Finance of the Russian Federation "The state and level of financial accessibility among the most excluded groups of consumers" noted the lack of knowledge and skills in the financial sphere.

Financial accessibility will be defined as the expansion of financial opportunities and access of the rural population and small businesses to credit and financial resources. It depends on the state policy that encourages access to official financial services and increases the economic activity of citizens and small and medium-sized businesses.

For small and micro-enterprises, access to financial resources is generally vital, and the availability of credit allows businesses to expand, create jobs, and reduce rural inequality. In developed countries, the level of financial inclusion is several times higher than in poor countries. For example, Switzerland, at the level of financial inclusion of 98.4\%, has a GDP at purchasing power parity per capita of $\$ 59.3$ thousand, and in Turkey, at 68.6\%, GDP at purchasing power parity per capita is $\$ 25.4$ thousand. In poor countries, the rates are even lower.

For citizens, access to financial resources facilitates their daily lives, helps families with planning, ranging from long-term goals to unforeseen situations. With a bank account, consumers are more likely to expand the list of financial services they use, making loans, investing in education and their own health, thus improving the overall quality and financial stability of life.

On the one hand, the financial involvement of the rural population is limited by the persistent digital inequality and insufficient financial and digital literacy, on the other - by low household incomes and their high debt burden. The specifics of agricultural production in the form of seasonal employment and the lack of a permanent income are also an obstacle to the use of credit products. For example, according to the monitoring of the Accounts Chamber of the Russian Federation, even rural mortgages under the state program "Integrated Development of Rural Territories" with such a preferential rate as 3 percent per annum, in 2020, only 1061 agricultural workers (4.4\%), 2870 employed in the social sphere (12\%) and 3375 representatives of municipal district administrations (14.1\%) could use. More than half of the loans for improving housing conditions were provided to citizens who do not permanently live in rural areas.

Studies have shown that, for at least 14 regions of the Russian Federation, rural mortgages are not affordable for workers engaged in agricultural production, since after deducting interest payments and repayment of principal; their incomes will fall below the subsistence minimum established in the region (Fig. 4). 


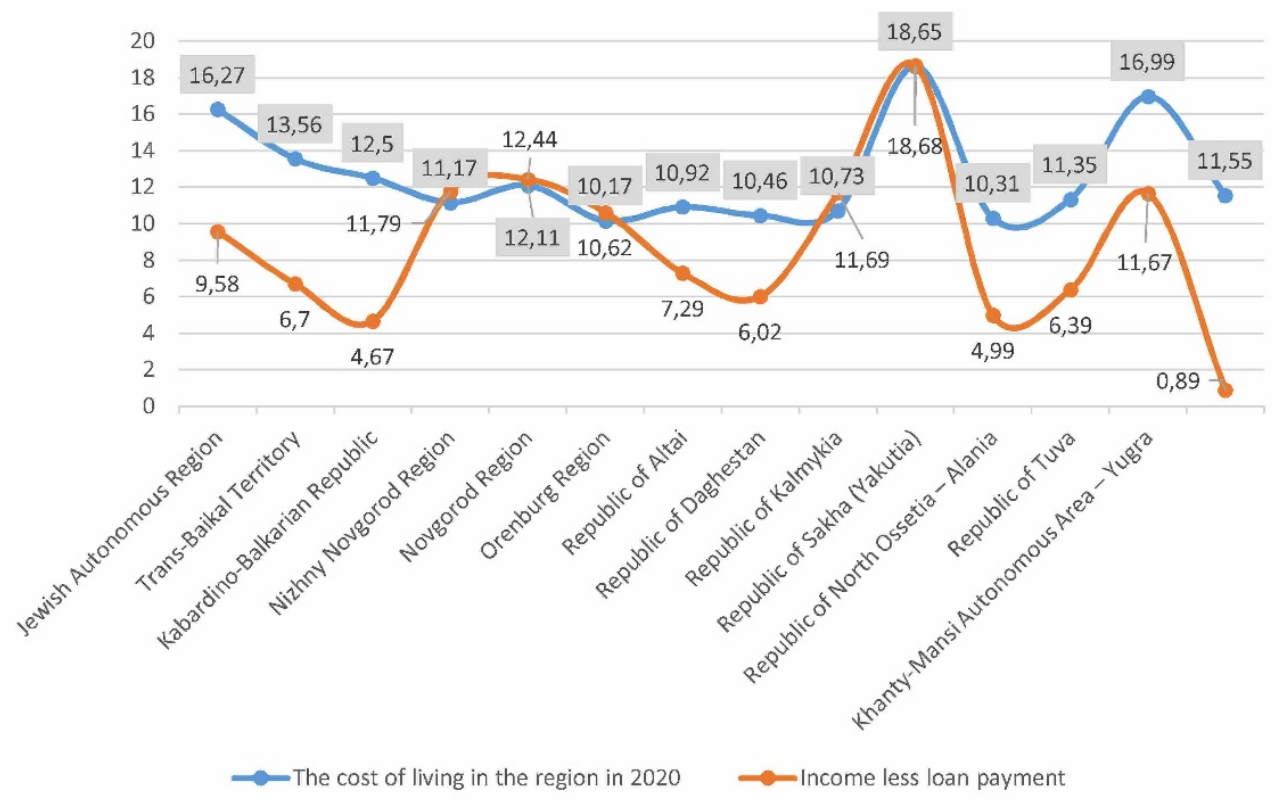

Fig. 4. Availability of rural mortgages in 2020 for workers engaged in agricultural production

Note: Compiled by the author on the basis of data from the Accounting Chamber of the Russian Federation

\section{Conclusion}

In the context of the active development of online platforms and digital financial technologies, in general, the availability and efficiency of obtaining financial services increases. However, rural areas of Russia are still not fully provided with a stable Internet and mobile communication. A significant threat to the development of financial inclusion can also be the low financial and digital literacy of the rural population. The persistent digital disparity in the level of provision of digital financial services in urban and rural areas deepens the gap not only in the development of access to financial instruments for rural residents, but also in the availability of information and the accumulation of knowledge in the field of financial management and improving the financial literacy of the rural population.

In order to promote the financial involvement of rural residents and small and mediumsized businesses, it is necessary to develop a system of measures to minimize barriers to inclusion in the financial system specifically for rural residents within the framework of existing state programs.

\section{References}

1. D.J. Snower Toward Global Paradigm Change: Beyond the Crisis of the Liberal World Order. - URL: https://t20japan.org/policy-brief-toward-global-paradigm-change/ (2018)

2. European Commission, Europe 2020. A European Strategy for Smart, Sustainable and Inclusive Growth (2010)

3. Ulaan Chultham, Bulletin of Baikal State University, 1, 66-72 (2016)

4. Trade and Development 2012.

URL: 
http://unctad.org/en/PublicationsLibrary/tdr2012_en.pdf

5. R. Ranieri, R.A. Ramos, After All, What is Inclusive Growth?, International Policy Centre for Inclusive Growth (IP C-IG). Originally published as IP C-IG’s One Pager № 188

6. The Inclusive Growth and Development Report 2017. - URL: http://reports. weforum.org/inclusive-growth-and-development-report-2017/.

7. The Inclusive Development Index 2018. - URL: https://www.weforum. org/reports/theinclusive-development-index-2018

8. A.N. Tarasov, A.S. Tarasov, N. Antonova, S. Podgorskaya, et al., Institutes and models in the management system of integrated rural development, «AzovPrint» Publishing House, 226 (2020)

9. N. Antonova, A. Malyuga, M. Tarasova, A. Tarasov, S. Podgorskaya, E. Markina, G. Bakhmatova, et al., Spatial development of Russian regions: Trends and models, «MiniType», 80 (2019)

10. I. Ushachev, L. Bondarenko, Analytical Bulletin of the Federation Council of the Federal Assembly of the Russian Federation, 5 (719), 13- 17 (2019)

11. Financial inclusion and the Sustainable Development Goals - URL: https://www.uncdf.org/financial-inclusion-and-the-sdgs

12. National Agency for Financial Research - URL: https://nafi.ru/analytics

13. The Global Findex Database 2017 // World Bank Group 